\title{
Sex differences in CRT device implantation rates, efficacy, and complications following implantation: protocol for a systematic review and meta-analysis of cohort studies
}

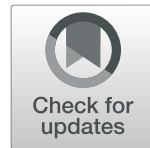

Omar Dewidar ${ }^{1,2^{*}}$ (D), David Birnie ${ }^{3}$, Irina Podinic ${ }^{1}$, Vivian Welch ${ }^{1,2+}$ and George A. Wells $s^{1,4 \dagger}$

\begin{abstract}
Introduction: There is abundant evidence for sex differences in the diagnosis, implantation, and outcomes for cardiac resynchronization therapy (CRT) devices. Controversial data suggesting women are less likely to receive the device regardless of the greater benefit. The aim of this review is to assess sex differences in the implantation rate, clinical effectiveness, and safety of patients receiving CRT devices.

Methods: We will conduct a systematic literature search of MEDLINE, Embase, and Web of Science to identify cohort studies that meet our eligibility criteria. Title and full text screening will be conducted in duplicate independently. Eligible studies report clinical effectiveness or safety of patients receiving CRT device while providing sex-disaggregated data. Implantation rate will be extracted from the baseline characteristics tables of the studies. The effectiveness outcomes include the following: all-cause death, hospitalization, peak oxygen consumption $\left(\mathrm{pVO}_{2}\right)$, quality of life (QoL), 6-min walk test, NYHA class reduction, LVEF, and heart failure hospitalization. The complication outcomes include the following: contrast-induced nephropathy, pneumothorax, pocket-related hematoma, pericardial tamponade, phrenic nerve stimulation, device infection, death, pulmonary edema, electrical storm, cardiogenic shock, and hypotension requiring resuscitation. Description of included studies will be reported in detail and outcomes will be meta-analyzed and presented using forest plots when feasible. Risk of bias will be assessed using the Newcastle-Ottawa Scale (NOS) by two review authors independently. GRADE approach will be used to assess the certainty of evidence.
\end{abstract}

Discussion: The aim of this review is to determine the presence of differences in CRT implantation between women and men as well as differences in clinical effectiveness and safety of CRT after device implantation. Results from this systematic review will provide important insights into sex differences in CRT devices that could contribute to the development of sex-specific recommendations and inform policy.

Systematic review registration: PROSPERO CRD42020204804

Keywords: Cardiac resynchronization therapy, Cardiac implantable electronic device, Efficacy, Complications, Implantation, Cohort, Sex differences, Non-randomized studies, Systematic review

\footnotetext{
* Correspondence: Odewi090@uottawa.ca

†Vivian Welch and George A. Wells are co-senior authors.

${ }^{1}$ School of Epidemiology and Public Health, University of Ottawa, 600 Peter

Morand Crescent, Ottawa, Ontario K1G 5Z3, Canada

${ }^{2}$ Bruyère Research Institute, University of Ottawa, 85 Primrose Ave, Ottawa,

Ontario K1R 6M1, Canada

Full list of author information is available at the end of the article
}

\section{$\triangle B M C$}

(c) The Author(s). 2021 Open Access This article is licensed under a Creative Commons Attribution 4.0 International License, which permits use, sharing, adaptation, distribution and reproduction in any medium or format, as long as you give appropriate credit to the original author(s) and the source, provide a link to the Creative Commons licence, and indicate if changes were made. The images or other third party material in this article are included in the article's Creative Commons licence, unless indicated otherwise in a credit line to the material. If material is not included in the article's Creative Commons licence and your intended use is not permitted by statutory regulation or exceeds the permitted use, you will need to obtain permission directly from the copyright holder. To view a copy of this licence, visit http://creativecommons.org/licenses/by/4.0/ The Creative Commons Public Domain Dedication waiver (http://creativecommons.org/publicdomain/zero/1.0/) applies to the data made available in this article, unless otherwise stated in a credit line to the data. 


\section{Background}

There are substantial behavioral and biological differences between men and women which affect the manifestation, epidemiology, and pathophysiology of diseases and potential therapies [1]. Sex and gender affect an array of diseases including cardiovascular disease [2]. Heart failure (HF), one of the most prevalent cardiovascular diseases, is the leading cause of cardiovascular morbidity and mortality in Canada and the world and also differentially impacts men and women in terms of risk and outcomes [3, 4]. Biological differences cause women to more frequently experience heart failure with atypical symptoms unlike men which results in underdiagnosis $[5,6]$.

Cardiac resynchronization therapy (CRT), also known as biventricular pacing is the latest cardiac implantable electronic device (CIED) aimed to reduce symptoms for $\mathrm{HF}$ and improve ventricular function heart. This device exists in two types: CRT-pacemaker (CRT-P), which synchronizes the heart beating pattern through improving the pumping action the lower ventricles, and CRTdefibrillator (CRT-D), which in addition to synchronizing heart rhythm, can detect and treat sudden cardiac death (SCD) [7]. International cardiovascular guidelines have declared CRT devices as the highest recommendation (class 1 indication) for patients with left ventricular ejection fraction (LVEF) $\leq 35 \%$, New York Heart Association (NYHA) heart failure classification 2, 3, or 4 symptoms (scale corresponding to patient's inability to conduct physical activity), left bundle block (LBBB) with a QRS duration $\geq 150 \mathrm{~ms}$, and sinus rhythm [8].

Sex differences are apparent in heart failure pathophysiology and etiology; however, the mechanisms remain not well understood [9]. An in-depth review of observational studies and trials assessing sex differences in heart failure therapies [10] reports controversial findings of underutilization of CRT devices in women compared to men [11-16] even though there is greater clinical benefit in women and diverse findings for adverse events [14, 17, 18]. Evidence from an individual participant data (IPD) network meta-analysis (MA) of 3 trials [19-21] $(n=4076)$ suggests that women with LBBB and QRS of $150 \mathrm{~ms}$ or longer benefited from CRT-D more than men, with $76 \%$ reduction in heart failure [22]. However, underrepresentation of women (only $20 \%$ of the total population) and variety in follow-up times $(1.1,2.2$, and 4.7 years across 3 trials) proposes cautious interpretation of the results.

A systematic review of randomized and non-randomized (NRS) CRT studies $(\mathrm{n}=183)$ suggests that women with CRT devices tend to have better LVEF reduction $<15 \%$ compared to men [23]. However, this review was conducted in 2015 and is of low quality as per AMSTAR 2 tool [24], with single database search (PubMed) in combination with study restriction via text search and absence of risk of bias
(RoB) assessment and inappropriate pooling of studies for MA among other issues [25].

Most of the previous SRs and MAs have focused on RCTs. However, to better interpret the effectiveness and safety of CRT devices across sex in the usual clinical setting, we will restrict to cohort studies as the results tend to be more generalizable [26], implantation rates will reflect real-world setting, overcome the issue of female underrepresentation in clinical trials [27], and spurious findings from post hoc subgroup analyses [28].

The objectives of this review are to formally assess sex differences in the (1) implantation rate, (2) clinical effectiveness, and (3) safety for patients receiving CRT devices.

\section{Methods}

This protocol was developed a priori to conducting the study. Any deviations will be reported in all related publications and the PROSPERO record (CRD42020204804) will be adapted accordingly. This systematic review protocol was developed using guidance from the Cochrane Handbook for Systematic Review of Interventions [29] and the Preferred Reporting Items for Systematic Review and Meta-Analysis Protocols (PRISMA-P) [30].

\section{Eligibility criteria \\ Participants}

This review will target patients $\geq 18$ years eligible for de novo implantation of CRT conforming with international guidelines [8]. Studies in which the population underwent device replacement will not be included; however, we will consider patients that received upgrade from ICD to CRT-D.

\section{Interventions}

The intervention of the included studies will be the CRT device in addition to follow-up from time of implantation of CRT in accordance to guidelines [31, 32]. Follow-up methods can be conducted virtually or by in clinic visits.

\section{Outcomes}

Studies must report outcomes disaggregated by sex or compare outcomes across sex.

Implantation rate Implantation rate will correspond to the frequency of device implantations for each sex as a proportion of the total number of implantations.

Effectiveness The definitions for the effectiveness outcomes are reported in Appendix 1 and were selected based on reporting in international clinical guidelines. Clinical efficacy outcomes include the following: all-cause mortality, hospitalization, peak oxygen consumption $\left(\mathrm{pVO}_{2}\right)$, quality of life (QoL), 6-min walk test, NYHA class reduction, LVEF, and heart failure hospitalization (defined in Appendix 1). 
Complications We plan to assess both clinical and mechanical complications as categorized by Krahn et al. [33] where mechanical complications stem from mechanical effects of the surgery, while clinical complications arise from new or worsening comorbidities. All the complications to be assessed will be "major" as they will require intervention to provide therapeutic relief [34]. Complications were classified short term if they occurred within 2 months of implantation and long term if they emerged thereafter [35]. We will assess the emergence of the following device complications (defined in Appendix 2): contrast-induced nephropathy, pneumothorax, pocket-related hematoma, pericardial tamponade, phrenic nerve stimulation, device infection, death, pulmonary edema, electrical storm, cardiogenic shock, and hypotension requiring resuscitation.

\section{Study designs}

We will include in our review cohort studies (prospective, retrospective). We will exclude randomized studies, case reports, case series, review articles, cross-sectional studies, surveys, qualitative or interview/focus group studies, editorials, letters, and commentaries.

\section{Setting}

No restrictions will be imposed on the type of setting.

\section{Language}

No language restriction will be applied.

\section{Information sources}

The search was conducted from the date January 1, 2000, to June 12, 2020, of the following databases: MEDLINE, Embase, and Web of Sciences. To ensure a thorough search, we will review the reference list of relevant systematic reviews for eligible studies.

\section{Search strategy}

With the assistance of an information specialist, we developed a comprehensive search strategy. The search strategy includes a combination of Medical Subject Headings (MeSH) and indexed terms and database-specific terms. Detailed description of the search strategies can be found in Appendix 3 .

Keywords used to develop this search are variations of the following terms: "Cardiac Implantable Electronic Device" or "Cardiac Resynchronization Therapy" or "Defibrillators" or "Implantable cardioverter defibrillator" or "heart failure" or "Cardiac failure" or "Biventricular Pacemaker". Due to the large number of studies retrieved (> 20,000), we will use the most up-to-date cohort study search filter developed by the Inter InterTASC Information Specialists' Sub-Group (ISSG) [36] to obtain observational studies. We also added variants of the terms: "Registry", "Prospective" and "Retrospective" for a more comprehensive search. To further narrow our search, we will use a validated heart failure search filter that retrieves studies focused on device therapy in heart failure context [37].

\section{Study selection and screening process}

Study selection will be conducted in a blinded fashion, by two independent reviews using Covidence program [38]. Screening at title and abstract stage and full text stages will be completed in duplicate. Discrepancies will be resolved by discussion between reviewers followed by consensus, or a third reviewer. We will prepare a PRISMA study flow chart. Studies that assess sex differences in outcomes for patients receiving CRT devices will be selected in duplicate, independently. We plan on capturing all outcomes reported in the studies that relate to the clinical effectiveness of the device, implantation rate across sex, and adverse events related to complications post implantation. ICD studies with $>50 \%$ CRT-D will be considered eligible and extracted. Studies with $>75 \%$ primary prevention will be extracted, and other studies will be listed with reason for exclusion (e.g., secondary prevention).

\section{Data collection}

Data extraction will be conducted by two independent reviewers using a pretested extraction form. Conflicts will be resolved by consensus between the two reviewers or by a third reviewer. The extraction form will be developed in collaboration with a content expert based on the Data Extraction Template for Cochrane Reviews [39]. The form will be pilot tested with a random sample of 5 studies and further developed accordingly. The extraction process will be facilitated using Microsoft Excel forms customized with extraction criteria.

\section{Data items}

The extraction form will be developed in collaboration with a content expert, and pilot tested with a random sample of 5 studies, and further developed accordingly.

Reviewers will extract data on study characteristics (name of author, publication date, journal, funding, and conflict of interest), study methodology (objectives, target population, recruitment and sampling procedures, setting), participant information (baseline characteristics, device type, disease severity classification, sample size), and outcomes (definitions, time of measurement, and results) (Appendix 1).

\section{Risk of bias and quality of assessment of individual studies}

We will be assessing non-randomized studies; therefore, we will be using the Newcastle-Ottawa Scale (NOS) tool to assess risk of bias [40]. Scale items assess selection of cases and controls, comparability of cases and controls, and outcome follow-up. Judgments will be made by two independent reviewers and disagreements will be resolved through discussion. 


\section{Synthesis of results}

We will meta-analyze quantitative data when appropriate. We will use $\mathrm{I}^{2}$ statistic to assess heterogeneity. An $\mathrm{I}^{2}$ value greater than $75 \%$ would indicate high heterogeneity. An $\mathrm{I}^{2}$ between 50 and $75 \%$ indicates moderate heterogeneity and calls for investigation via post hoc subgroup analysis [41]. We will conduct meta-analysis using random effects methodology using Revman [42]. When meta-analysis is inappropriate due to comparative diversity, results will be narratively reported while providing effect sizes and confidence intervals. Individual and pooled analyses will be presented using tables and forest plots, respectively.

Interventions that involve implantation of CRT-P and CRT-D will be treated separately. All the extracted outcomes will be analyzed separately. Categorical outcomes will be assessed using risk ratios (95\% confidence intervals $(\mathrm{CI})$ ) and continuous outcomes will be analyzed using mean differences (95\% CI) [43].

An intention to treat analysis method will be adopted. We will record how authors dealt with missing data and sensitivity analysis will be used to investigate the effect of missing data on the overall results. Adjusted results reported in the included studies as effect measures will be used in the analyses accordingly.

\section{Subgroup analysis}

Where feasible and appropriate, we will conduct exploratory subgroups to investigate the impact of factors on outcomes. We plan on conducting a priori subgroup analysis for the following criteria:

- Age $(<65, \geq 65)$

- Type of device (CRT-D, CRT-P)

- Disease severity (NYHA class I-II, NYHA class III-IV)

- QRS morphology (LBBB, non-LBBB)

- Heart failure etiology (ischemic, non-ischemic)

\section{Sensitivity analysis}

Sensitivity analysis may be considered with respect to composition of the participants or definitions of outcomes to assess the robustness of the performed meta-analysis. We will inspect publication bias using funnel plots in the case of 10 or more studies are included in our review [44]. We will display the meta-analyzed results using forest plots.

\section{Strength of evidence assessment}

We will use the GRADE framework to rate the certainty of the evidence of intervention effects [45]. GRADE assessment will be conducted in duplicate by two reviewers, independently. Discrepancies will be resolved by discussion or a third reviewer. Summarized results will be presented as summary of findings tables [45].

\section{Discussion}

The aim of this review is to determine the presence of differences in CRT implantation between women and men as well as differences in efficacy and safety of CRT post device implantation. We anticipate our systematic review will provide important insights into sex differences in CRT devices that could eventually lead to develop sex-specific recommendations and inform policy.

A potential limitation to this review is the inability to retrieve disaggregated data for some of the included studies that do not report data in the manuscript. We will not attempt to contact authors for sex-specific data as we predict a high yield of eligible studies and anticipate little reward with contacting as it is a timeconsuming process. However, our pilot search has identified several studies with disaggregated data so this will not impede the ability to conduct quantitative metaanalysis. We also acknowledge that implementing our search filters restricting by study design and heart failure topic may result in missing eligible studies, but we plan on hand searching eligible systematic reviews to ensure a complete search.

We acknowledge that acquiring measures of effect from NRS is not always reliable due to confounding and other biases. However, several reviews have indicated that the results of NRS correspond generally with the results from trials when properly designed with appropriate accounting for covariates [46-50], providing accurate estimates of effects in real-world practice setting. In addition, ethical issues arise with conducting RCTs primarily aimed at assessing therapies that are already implemented in health policy due to equipoise. In general, RCTs for surgical treatments are of poor methodological quality due to difficulties in randomization, incapability of blinding, and small sample sizes [51, 52]. Therefore, treatment information is primarily obtained from NRS evidence [53, 54]. This paradigm remains valid for cardiac surgery studies as there is a significant reduction in the number of RCTs over the years [55].

Furthermore, the absence of participant restrictions in observational studies makes them well suited to study effects on health inequities which are differences in health that are avoidable and unfair [56]. Patient-physician gender, patient preference, and gender bias impact the choice and efficacy of cardiovascular interventions [5759]. The use of RCTs to investigate this question will be inadequate since researchers manipulate the enrolment of participants.

We are aware that observational studies cannot replace RCTs as they provide high internal validity and comparability, but RCTs cannot be axiomatic. Results from both study designs can complement each other to fill gaps in clinical knowledge and contribute to decision making. 


\section{Appendix 1}

Table 1 Definitions of efficacy outcomes

\section{Efficacy outcomes}

6-min walk test

NYHA class reduction

LVEF improvement

Peak oxygen consumption $\left(\mathrm{pVO}_{2}\right)$

Hospitalization

All-cause mortality

Quality of life

Heart failure hospitalization

Composite response endpoint

All-cause mortality composite outcomes

\section{Definitions}

Treadmill walking test to test exercise capacity in patients with chronic heart failure [60].

Estimation of NYHA functional class [61] within 6 months after randomization [62]

Measured using 2-dimenionsonal Doppler-flow echocardiography [63] or used LV volume reduction

Measurement of peak oxygen consumption per unit time at anaerobic threshold. The improvement will be assessed from baseline to 6 months [64]

NA

NA

Questionnaire developed to assess patients perception on the impact of heart failure on their daily lifestyle [65] Includes patients that were admitted to any health facility for the treatment of heart failure symptoms for more than 24 h [66]

Worsened: Patient death, worsening of heart failure resulting in hospitalization, therapeutic response is considered insufficient, worsening in NYHA class relative to previous observation or moderate-marked worsening of patient global assessment score at LOCF (last observation carried forward).

Improved: Patient has not worsened (as previously described) and shows improvement in NYHA class at LOCF and/or moderate-marked improvement in patient global assessment score at LOCF.

Unchanged: No indications of worsened nor improved health of patients [62].

All-cause mortality in combination with any other outcomes 


\section{Appendix 2}

Table 2 Definitions of safety outcomes

\begin{tabular}{|c|c|c|}
\hline $\begin{array}{l}\text { Short term or } \\
\text { long term }\end{array}$ & Complications & Definition \\
\hline \multicolumn{3}{|l|}{ Mechanical } \\
\hline Long term & $\begin{array}{l}\text { Lead-related complications (i.e., } \\
\text { dislodgement, lead malposition) }\end{array}$ & Presence of lead malfunction requiring reoperation [67] \\
\hline $\begin{array}{l}\text { Short term or } \\
\text { long term }\end{array}$ & Device infection & $\begin{array}{l}\text { Hospitalization for proven CIED infection within } 1 \text { year of implantation. Infection is } \\
\text { categorized into pocket infection, bloodstream infection, and endocarditis [68]. }\end{array}$ \\
\hline Short term & Contrast-induced nephropath & $\begin{array}{l}\text { Contrast nephropathy was defined as an increase in serum creatinine of } 25 \% \text { or greater } \\
\text { within } 48 \mathrm{~h} \text { after contrast administration. Contrast nephropathy was defined as an increase } \\
\text { in serum creatinine of } 25 \% \text { or greater within } 48 \mathrm{~h} \text { after contrast administration. Contrast } \\
\text { nephropathy was defined as an increase in serum creatinine of } 25 \% \text { or greater within } 48 \mathrm{~h} \\
\text { after contrast administration. } \\
\text { Contrast nephropathy was defined as an increase in serum creatinine of } 25 \% \text { or greater } \\
\text { within } 48 \mathrm{~h} \text { after contrast administration which would lead to dialysis [69]. }\end{array}$ \\
\hline Short term & $\begin{array}{l}\text { Pneumothorax (related to venous } \\
\text { access) }\end{array}$ & $\begin{array}{l}\text { Complications while obtaining venous access during the index hospitalization including } \\
\text { the absence of lung markings over the lung field ipsilateral to the PM pocket assessed } \\
\text { from the predischarge X-ray [70]. }\end{array}$ \\
\hline Short term & Pocket-related Hematoma & $\begin{array}{l}\text { Hematoma requiring further surgery, resulting in prolongation of hospitalization, or } \\
\text { requiring interruption of oral anticoagulation therapy. Prolongation of hospitalization was } \\
\text { defined as extended hospitalization or rehospitalization for at least } 24 \mathrm{~h} \text { after the index } \\
\text { surgical procedure, primarily due to the hematoma [71]. }\end{array}$ \\
\hline Short term & Pericardial tamponade & $\begin{array}{l}\text { Slow or rapid compression of the heart due to the pericardial accumulation of fluid, pus, } \\
\text { blood, clots, or gas, as a result of effusion, trauma, or rupture of the heart [72]. }\end{array}$ \\
\hline Short term & $\begin{array}{l}\text { Phrenic nerve stimulation requiring } \\
\text { reoperation }\end{array}$ & $\begin{array}{l}\text { PS tested during follow-up of patients starting from maximum pacing system analyzer out- } \\
\text { put, } 10 \mathrm{~V} \text { at } 1.5 \text { ms followed by a stepping down protocol. In the event of PS occurrence, } \\
\text { its threshold is measured in all the possible pacing configurations and compared with LV } \\
\text { pacing threshold to ensure the feasibility of biventricular stimulation. } \\
\text { PS disappearance was defined as absence of muscular stimulation over a 20-min observa- } \\
\text { tion period during respiratory changes (deep breath); LV threshold was defined as } 100 \% \\
\text { stimulation during the same respiratory changes and requires reoperation [73]. }\end{array}$ \\
\hline \multicolumn{3}{|l|}{ Clinical } \\
\hline Short term & Death & $\begin{array}{l}\text { Clinical death was considered to be when spontaneous respirations ceased, and pulse and } \\
\text { blood pressure disappeared [74].. } \\
\text { Cause of death of patients before their first outpatient visit must be established by } \\
\text { reviewing patient charts to identify relation to procedure [75]. }\end{array}$ \\
\hline Short term & Electrical storm & $\begin{array}{l}\text { Electric storm in patients with CRT-D is defined as } \geq 3 \text { adequate detections of } V T \text { and/or } \\
V F \text { in } 24 \mathrm{~h} \text { terminated with ATP or high-voltage therapy }(\mathrm{HVT}) \text {, or untreated sustained VT } \\
\text { recorded in the monitoring zone over } 1 \text { week after the implantation [76-79]. }\end{array}$ \\
\hline Short term & Pulmonary edema & NA \\
\hline Short term & Cardiogenic shock & $\begin{array}{l}\text { Defined as hypotension (SBP, } 90 \mathrm{mmHg} \text { ) despite adequate filling status with signs of } \\
\text { hypoperfusion [80]. }\end{array}$ \\
\hline Short term & Hypotension requiring resuscitation & NA \\
\hline
\end{tabular}

\section{Appendix 3}

Detailed search strategy

MEDLINE:

1. CIED or (Cardiac adj2 implant* adj2 electronic* adj2 device?)).ti,ab.

2. defibrillators, implantable/ or exp pacemaker, artificial/

3. ((biventricular adj2 pacemaker*) or pacemaker*).ti,ab.

4. ((resynch* or re-synch*) adj3 (cardiac or therap* or treatment* or device $\left.\left.{ }^{*}\right)\right)$.ti,ab.

5. (cardioconver* or (cardio adj conver*)).ti,ab.
6. 1 or 2 or 3 or 4 or 5

7. exp cohort studies/

8. cohort\$.tw.

9. controlled clinical trial.pt.

10. epidemiologic methods/

11. limit 10 to $\mathrm{yr}=1971-1988$

12. or $/ 7-9,11$

13. (registr* or Prospective* or Retrospective*).mp.

14. 12 or 13

15. heart failure.mp.

16. ventricular dysfunction, left.sh.

17. cardiomyopathy.mp.

18. left ventricular ejection fraction.mp. 
19. or/13-16

20. 6 and 14 and 19

21. limit 20 to $y r=$ "2000 -Current"

Embase:

1. CIED or (Cardiac adj2 implant* adj2 electronic* adj2 device?)).ti,ab.

2. cardiac implantable electronic device/ or exp cardiac resynchronization therapy device/

3. exp biventricular implantable cardioverter defibrillator/ or exp cardiac resynchronization therapy defibrillator/ or exp dual chamber implantable cardioverter defibrillator/

4. exp defibrillator pacemaker/

5. ((biventricular adj2 pacemaker*) or pacemaker*).ti,ab.

6. ((resynch* or re-synch*) adj3 (cardiac or therap* or treatment* or device $\left.\left.{ }^{*}\right)\right)$.ti,ab.

7. (cardioconver* or (cardio adj conver*)).ti,ab.

8. 1 or 2 or 3 or 4 or 5 or 6 or 7

9. exp cohort analysis/

10. exp longitudinal study/

11. exp prospective study/

12. exp follow up/

13. cohort\$.tw.

14. or $/ 9-13$

15. (registr* or Prospective* or Retrospective*).mp.

16. 14 or 15

17. heart failure.mp.

18. ventricular dysfunction, left.sh.

19. cardiomyopathy.mp.

20. left ventricular ejection fraction.mp.

21. or/15-18

22. 8 and 16 and 21

23. limit 22 to $y r=$ "2000 -Current"

24. (conference abstract or conference review).pt.

25. 23 not 24

\section{Web of Science}

1. $\mathrm{TS}=(\mathrm{CIED}$ or $($ Cardiac NEAR/2 implant* NEAR/2 electronic $^{*}$ NEAR/2 device $\left.{ }^{*}\right)$ )

2. TS=((biventricular NEAR/2 pacemaker*) or pacemaker*)

3. $\mathrm{TS}=(($ resynch* or re-synch*) NEAR/3 (cardiac or therap* or treatment* or device $\left.\left.{ }^{*}\right)\right)$

4. TS $=($ cardioconver* or (cardio adj conver*) $)$

5. 1 or 2 or 3 or 4

6. TS="heart failure"

7. $\mathrm{TS}=\left(\right.$ left ventric ${ }^{*} \mathrm{NEAR} / 2$ "dysfunction")

8. TS=(left ventric* NEAR/2 "ejection fraction")

9. 6 or 7 or 8 or 9

10. 10 and 5
11. $\mathrm{TS}=$ Cohort

12. TS=longitudinal*

13. $\mathrm{TS}=$ prospective ${ }^{*}$

14. TS="follow up"

15. $\mathrm{TS}=$ registr*

16. $\mathrm{TS}=$ Retrospective $^{*}$

17. 11 or 12 or 13 or 14 or 15 or 16

18. 18 and 11

\section{Abbreviations}

HF: Heart failure; CRT: Cardiac resynchronization therapy; CIED: Cardiac implantable electronic device; CRT-P: Cardiac resynchronization therapypacemaker; CRT-D: Cardiac resynchronization therapy-defibrillator; LVEF: Left ventricular ejection fraction; LBBB: Left bundle block branch; PRIS MA: Preferred Reporting Items for Systematic Review and Meta-Analysis; PRIS MA-P: Preferred Reporting Items for Systematic Review and Meta-Analysis Protocols; QoL: Quality of life

\section{Acknowledgements}

The authors would to like to acknowledge Sarah Visintini for assisting in the conduction of the search strategy.

\section{Authors' contributions}

$\mathrm{OD}$ is the guarantor and prepared the manuscript. All other authors contributed to the development of the eligibility and data extraction criteria. OD developed the search criteria. The authors have read and approved the final manuscript. WW and GW are senior co-authors.

\section{Funding}

Omar Dewidar is funded by the Bruyère Research Institute through a Graduate Student scholarship. The funder had no role in the design of the study or in writing the manuscript.

Availability of data and materials Not applicable.

\section{Declarations}

Ethics approval and consent to participate

Not applicable.

Consent for publication

Not applicable.

\section{Competing interests}

The authors declare that they have no competing interests.

\section{Author details}

${ }^{1}$ School of Epidemiology and Public Health, University of Ottawa, 600 Peter Morand Crescent, Ottawa, Ontario K1G 5Z3, Canada. ${ }^{2}$ Bruyère Research Institute, University of Ottawa, 85 Primrose Ave, Ottawa, Ontario K1R 6M1, Canada. ${ }^{3}$ Division of Cardiology, Department of Medicine, University of Ottawa Heart Institute, 40 Ruskin St, Ottawa, Ontario K1Y 4W7, Canada. ${ }^{4}$ Cardiovascular Research Methods Centre, University of Ottawa Heart Institute, 40 Ruskin St, Ottawa, Ontario K1Y 4W7, Canada.

Received: 14 October 2020 Accepted: 15 June 2021

Published online: 23 July 2021

\section{References}

1. Regitz-Zagrosek V. Sex and gender differences in health. Science \& Society Series on Sex and Science. EMBO Rep. 2012;13(7):596-603. https://doi.org/1 $0.1038 /$ embor.2012.87.

2. Oertelt-Prigione S, Regitz-Zagrosek V. Sex and gender aspects in clinical medicine. London, UK: Springer; 2012. https://doi.org/10.1016/j.autrev.2 011.11.022.

3. Blair JE, Huffman M, Shah SJ. Heart failure in North America. Curr Cardiol Rev. 2013;9(2):128-46. https://doi.org/10.2174/1573403X11309020006. 
4. Maas AH, Appelman YE. Gender differences in coronary heart disease. Neth Hear J. 2010;18(12):598-602. https://doi.org/10.1007/s12471-010-0841-y.

5. Regitz-Zagrosek V, Oertelt-Prigione S, Seeland U, Hetzer R. Sex and gender differences in myocardial hypertrophy and heart failure. Circ J. 2010;74(7): 1265-73. https://doi.org/10.1253/circj.CJ-10-0196.

6. Regitz-Zagrosek $V$. Sex and gender differences in symptoms of myocardial ischaemia. Eur Heart J. 2011;32(24):3064-6. https://doi.org/10.1093/eurheartj/ ehr272.

7. Bax JJ, Abraham T, Barold SS, Breithardt OA, Fung JW, Garrigue S, et al. Cardiac resynchronization therapy: part 1--issues before device implantation. J Am Coll Cardiol. 2005;46(12):2153-67.

8. Exner DV, Birnie DH, Moe G, Thibault B, Philippon F, Healey JS, et al. Canadian Cardiovascular Society guidelines on the use of cardiac resynchronization therapy: evidence and patient selection. Can J Cardiol. 2013:29(2):182-95. https://doi.org/10.1016/j.cjca.2012.10.006.

9. Beale AL, Meyer P, Marwick TH, Lam CSP, Kaye DM. Sex differences in cardiovascular pathophysiology: why women are overrepresented in heart failure with preserved ejection fraction. Circulation. 2018;138(2):198-205. https://doi.org/10.1161/CIRCULATIONAHA.118.034271.

10. Hsich EM. Sex differences in advanced heart failure therapies. Circulation. 2019;139(8):1080-93. https://doi.org/10.1161/CIRCULATIONAHA.118.037369.

11. Chatterjee NA, Borgquist R, Chang Y, Lewey J, Jackson VA, Singh JP, et al. Increasing sex differences in the use of cardiac resynchronization therapy with or without implantable cardioverter-defibrillator. Eur Heart J. 2017; 38(19):1485-94. https://doi.org/10.1093/eurheartj/ehw598.

12. Randolph TC, Hellkamp AS, Zeitler EP, Fonarow GC, Hernandez AF, Thomas $\mathrm{KL}$, et al. Utilization of cardiac resynchronization therapy in eligible patients hospitalized for heart failure and its association with patient outcomes. Am Heart J. 2017;189:48-58. https://doi.org/10.1016/j.ahj.2017.04.001.

13. Lund LH, Braunschweig F, Benson L, Ståhlberg M, Dahlström U, Linde C. Association between demographic, organizational, clinical, and socioeconomic characteristics and underutilization of cardiac resynchronization therapy: results from the Swedish Heart Failure Registry. Eur J Heart Fail. 2017;19(10):1270-9. https://doi.org/10.1002/ejhf.781.

14. Sridhar AR, Yarlagadda V, Parasa S, Reddy YM, Patel D, Lakkireddy D, et al. Cardiac resynchronization therapy: US trends and disparities in utilization and outcomes. Circ Arrhythm Electrophysiol. 2016;9(3):e003108. https://doi. org/10.1161/CIRCEP.115.003108.

15. Schneider PM, Pellegrini CN, Wang Y, Fein AS, Reynolds MR, Curtis JP, et al. Prevalence of quideline-directed medical therapy among patients receiving cardiac resynchronization therapy defibrillator implantation in the National Cardiovascular Data Registry during the years 2006 to 2008. Am J Cardiol. 2014;113(12):2052-6. https://doi.org/10.1016/j.amjcard.2014.03.049.

16. Alaeddini J, Wood MA, Amin MS, Ellenbogen KA. Gender disparity in the use of cardiac resynchronization therapy in the United States. Pacing Clin Electrophysiol. 2008;31(4):468-72. https://doi.org/10.1111/j.1540-8159.2008.01 016.x

17. Jamerson D, McNitt S, Polonsky S, Zareba W, Moss A, Tompkins C. Early procedure-related adverse events by gender in MADIT-CRT. J Cardiovasc Electrophysiol. 2014;25(9):985-9. https://doi.org/10.1111/jce.12438.

18. Ghanbari H, Feldman D, Schmidt M, Ottino J, Machado C, Akoum N, et al. Cardiac resynchronization therapy device implantation in patients with therapeutic international normalized ratios. Pacing Clin Electrophysiol. 2010; 33(4):400-6. https://doi.org/10.1111/j.1540-8159.2010.02703.x.

19. Moss AJ, Hall WJ, Cannom DS, Klein H, Brown MW, Daubert JP, et al. Cardiacresynchronization therapy for the prevention of heart-failure events. N Engl J Med. 2009;361(14):1329-38. https://doi.org/10.1056/NEJMoa0906431.

20. Tang AS, Wells GA, Talajic M, Arnold MO, Sheldon R, Connolly S, et al. Cardiac-resynchronization therapy for mild-to-moderate heart failure. N Engl J Med. 2010;363(25):2385-95. https://doi.org/10.1056/NEJMoa1009540.

21. Linde C, Abraham WT, Gold MR, St John Sutton M, Ghio S, Daubert C, et al. Randomized trial of cardiac resynchronization in mildly symptomatic heart failure patients and in asymptomatic patients with left ventricular dysfunction and previous heart failure symptoms. J Am Coll Cardiol. 2008:52(23):1834-43.

22. Zusterzeel R, Selzman KA, Sanders WE, Caños DA, O'Callaghan KM, Carpenter $\mathrm{J}$, et al. Cardiac resynchronization therapy in women: US Food and Drug Administration meta-analysis of patient-level data. JAMA Intern Med. 2014;174(8):1340-8. https://doi.org/10.1001/jamainternmed.2014.2717.

23. Herz ND, Engeda J, Zusterzeel R, Sanders WE, O'Callaghan KM, Strauss DG, et al. Sex differences in device therapy for heart failure: utilization, outcomes, and adverse events. J Women's Health (Larchmt). 2015;24(4):26171.

24. Shea BJ, Reeves BC, Wells G, Thuku M, Hamel C, Moran J, et al. AMSTAR 2: a critical appraisal tool for systematic reviews that include randomised or non-randomised studies of healthcare interventions, or both. Bmj. 2017;358: j4008. https://doi.org/10.1136/bmj.j4008.

25. McKenzie JE, Brennan SE, Ryan RE, Thomson HJ, Johnston RV, Thomas J. Defining the criteria for including studies and how they will be grouped for the synthesis. Cochrane Handbook for Systematic Reviews of Interventions. 2019:33-65.

26. Carlson MD, Morrison RS. Study design, precision, and validity in observational studies. J Palliat Med. 2009;12(1):77-82. https://doi.org/10.1 089/jpm.2008.9690.

27. Sun X, Briel M, Busse JW, You JJ, Akl EA, Mejza F, et al. Credibility of claims of subgroup effects in randomised controlled trials: systematic review. BMJ. 2012;344:e1553. https://doi.org/10.1136/bmj.e1553.

28. Rothwell PM. Treating individuals 2. Subgroup analysis in randomised controlled trials: importance, indications, and interpretation. Lancet. 2005; 365(9454):176-86. https://doi.org/10.1016/S0140-6736(05)17709-5.

29. Julian H, James T, Jacqueline C, Miranda C, Tianjing L, Matthew P, et al. Cochrane Handbook for Systematic Reviews of Interventions. 2nd Edition ed. Chichester (UK): John Wiley \& Sons; 2019. https://doi.org/10.3354/dao03357.

30. Moher D, Shamseer L, Clarke M, Ghersi D, Liberati A, Petticrew M, et al. Preferred reporting items for systematic review and meta-analysis protocols (PRISMA-P) 2015 statement. Systematic Reviews. 2015:4(1):1.

31. Gillis AM, Philippon F, Cassidy MR, Singh N, Dorian P, Love BA, et al. Guidelines for implantable cardioverter defibrillator follow-up in Canada: a consensus statement of the Canadian Working Group on Cardiac Pacing. Can J Cardiol. 2003;19(1):21-37.

32. Brignole $M$, Auricchio A, Baron-Esquivias G, Bordachar P, Boriani G, Breithardt OA, et al. 2013 ESC Guidelines on cardiac pacing and cardiac resynchronization therapy: the Task Force on cardiac pacing and resynchronization therapy of the European Society of Cardiology (ESC). Developed in collaboration with the European Heart Rhythm Association (EHRA). Eur Heart J. 2013;34(29):2281-329.

33. Krahn Andrew D, Lee Douglas S, Birnie D, Healey Jeffrey S, Crystal E, Dorian P, et al. Predictors of short-term complications after implantable cardioverterdefibrillator replacement. Circ Arrhythm Electrophysiol. 2011;4(2):136-42.

34. Gould PA, Krahn AD. Canadian Heart Rhythm Society Working Group on Device Advisories ft. complications associated with implantable cardioverter-defibrillator replacement in response to device advisories. JAMA. 2006;295(16):1907-11. https://doi.org/10.1001/jama.295.16.1907.

35. Wilkoff BL, Auricchio A, Brugada J, Cowie M, Ellenbogen KA, Gillis AM, et al. HRS/EHRA Expert Consensus on the Monitoring of Cardiovascular Implantable Electronic Devices (CIEDs): description of techniques, indications, personnel, frequency and ethical considerations: developed in partnership with the Heart Rhythm Society (HRS) and the European Heart Rhythm Association (EHRA); and in collaboration with the American College of Cardiology (ACC), the American Heart Association (AHA), the European Society of Cardiology (ESC), the Heart Failure Association of ESC (HFA), and the Heart Failure Society of America (HFSA). Endorsed by the Heart Rhythm Society, the European Heart Rhythm Association (a registered branch of the ESC), the American College of Cardiology, the American Heart Association. Europace. 2008;10(6):707-25.

36. Study design search filters: BMJ Best Practice; [Available from: https:// bestpractice.bmj.com/info/toolkit/learn-ebm/study-design-search-filters/.

37. Damarell RA, Tieman J, Sladek RM, Davidson PM. Development of a heart failure filter for Medline: an objective approach using evidence-based clinical practice guidelines as an alternative to hand searching. BMC Med Res Methodol. 2011;11:12.

38. Innovation VH. Covidence systematic review software. Melbourne. Australia.

39. Li T, Higgins JPT, Deeks JJ. Collecting data. Cochrane Handbook for Systematic Reviews of Interventions. 2019:109-41.

40. Wells, G.A., Shea, B., O'Connell, D.A., Peterson, J., Welch, V., Losos, M., et al. The Newcastle-Ottawa Scale (NOS) for assessing the quality of nonrandomised studies in meta-analyses 2013 [Available from: http://www. ohri.ca/programs/clinical_epidemiology/oxford.asp.

41. Higgins JPT, Li T, Deeks JJ. Choosing effect measures and computing estimates of effect. Cochrane Handbook for Systematic Reviews of Interventions. 2019:143-76. 
42. Collaboration TC. Review Manager Web (RevMan Web); 2019. https://doi. org/10.17226/25375.

43. Deeks JJ, Higgins JPT, Altman DG, on behalf of the Cochrane Statistical Methods G. Analysing data and undertaking meta-analyses. Cochrane Handbook for Systematic Reviews of Interventions; 2019. p. 241-84.

44. Page MJ, Higgins JPT, Sterne JAC. Assessing risk of bias due to missing results in a synthesis. Cochrane Handbook for Systematic Reviews of Interventions. 2019:349-74.

45. Schünemann HJ, Higgins JPT, Vist GE, Glasziou P, Ak EA, Skoetz N, et al. Completing 'summary of findings' tables and grading the certainty of the evidence. Cochrane Handbook for Systematic Reviews of Interventions. 2019:375-402.

46. Ioannidis JP, Haidich AB, Pappa M, Pantazis N, Kokori SI, Tektonidou MG, et al. Comparison of evidence of treatment effects in randomized and nonrandomized studies. JAMA. 2001;286(7):821-30. https:/doi.org/10.1001/jama.286.7.821.

47. Wijeysundera DN, Beattie WS, Djaiani G, Rao V, Borger MA, Karkouti K, et al. Off-pump coronary artery surgery for reducing mortality and morbidity: meta-analysis of randomized and observational studies. J Am Coll Cardiol. 2005;46(5):872-82.

48. Hartz A, Bentler S, Charlton M, Lanska D, Butani Y, Soomro GM, et al. Assessing observational studies of medical treatments. Emerging themes in epidemiology [Internet]. 2005 2005/09//; 2:[8 p.]. Available from: http:// europepmc.org/abstract/MED/16137327Available from: https://doi.org/10.11 86/1742-7622-2-8Available from: https://europepmc.org/articles/PMC1215501A vailable from: https://europepmc.org/articles/PMC1215501?pdf=render.

49. Benson K, Hartz AJ. A comparison of observational studies and randomized, controlled trials. N Engl J Med. 2000;342(25):1878-86. https://doi.org/10.1 056/NEJM200006223422506.

50. Concato J, Shah N, Horwitz Rl. Randomized, controlled trials, observational studies, and the hierarchy of research designs. N Engl J Med. 2000;342(25): 1887-92. https://doi.org/10.1056/NEJM200006223422507.

51. Cook JA. The challenges faced in the design, conduct and analysis of surgical randomised controlled trials. Trials. 2009;10:9.

52. McCulloch P, Taylor I, Sasako M, Lovett B, Griffin D. Randomised trials in surgery: problems and possible solutions. BMJ. 2002;324(7351):1448-51. https://doi.org/10.1136/bmj.324.7351.1448.

53. Ellis J, Mulligan I, Rowe J, Sackett DL. Inpatient general medicine is evidence based. A-Team, Nuffield Department of Clinical Medicine. Lancet. 1995; 346(8972):407-10

54. Howes N, Chagla L, Thorpe M, McCulloch P. Surgical practice is evidence based. Br J Surg. 1997:84(9):1220-3.

55. Gaudino M, Kappetein AP, Di Franco A, Bagiella E, Bhatt DL, Boening A, et al. Randomized trials in cardiac surgery. J Am Coll Cardiol. 2020;75(13): 1593. https://doi.org/10.1016/j.jacc.2020.01.048.

56. Whitehead $\mathrm{M}$. The concepts and principles of equity and health. Int J Health Serv. 1992;22(3):429-45. https://doi.org/10.2190/986L-LHQ6-2VTE-YRRN.

57. Sandhu H, Adams A, Singleton L, Clark-Carter D, Kidd J. The impact of gender dyads on doctor-patient communication: a systematic review. Patient Educ Couns. 2009;76(3):348-55. https://doi.org/10.1016/.jpec.2009.07.010.

58. Carnlöf C, Iwarzon M, Jensen-Urstad M, Gadler F, Insulander P. Women with PSVT are often misdiagnosed, referred later than men, and have more symptoms after ablation. Scand Cardiovasc J. 2017;51(6):299-307. https:// doi.org/10.1080/14017431.2017.1385837.

59. Linde C, Bongiorni MG, Birgersdotter-Green U, Curtis AB, Deisenhofer I, Furokawa T, et al. Sex differences in cardiac arrhythmia: a consensus document of the European Heart Rhythm Association, endorsed by the Heart Rhythm Society and Asia Pacific Heart Rhythm Society. Europace. 2018;20(10):1565-ao.

60. Guyatt GH, Sullivan MJ, Thompson PJ, Fallen EL, Pugsley SO, Taylor DW, et al. The 6-minute walk: a new measure of exercise capacity in patients with chronic heart failure. Can Med Assoc J. 1985;132(8):919-23.

61. Dolgin M, Criteria Committee of the New York Heart A, New York Heart Association. Criteria C, Fox AC, Levin RI. Nomenclature and criteria for diagnosis of diseases of the heart and great vessels: Little, Brown; 1994.

62. Abraham WT. Rationale and design of a randomized clinical trial to assess the safety and efficacy of cardiac resynchronization therapy in patients with advanced heart failure: the Multicenter InSync Randomized Clinical Evaluation (MIRACLE). J Card Fail. 2000;6(4):369-80. https://doi.org/10.1054/jcaf.2000.20841.

63. Young JB, Abraham WT, Smith AL, Leon AR, Lieberman R, Wilkoff B, et al. Combined cardiac resynchronization and implantable cardioversion defibrillation in advanced chronic heart failure: the MIRACLE ICD Trial. JAMA. 2003;289(20):2685-94. https://doi.org/10.1001/jama.289.20.2685.
64. Bristow MR, Feldman AM, Saxon LA. Heart failure management using implantable devices for ventricular resynchronization: Comparison of Medical Therapy, Pacing, and Defibrillation in Chronic Heart Failure (COMPANION) trial. COMPANION Steering Committee and COMPANION Clinical Investigators. J Card Fail. 2000;6(3):276-85. https://doi.org/10.1054/jcaf.2000.9501.

65. Rector TS, Kubo SH, Cohn JN. Validity of the Minnesota Living with Heart Failure questionnaire as a measure of therapeutic response to enalapril or placebo. Am J Cardiol. 1993;71(12):1106-7. https://doi.org/10.1016/0002-9149(93)90582-W.

66. Tang AS, Wells GA, Arnold M, Connolly S, Hohnloser S, Nichol G, et al. Resynchronization/defibrillation for ambulatory heart failure trial: rationale and trial design. Curr Opin Cardiol. 2009;24(1):1-8. https://doi.org/10.1097/ HCO.0b013e32831 bc63b.

67. Poole JE, Gleva MJ, Mela T, Chung MK, Uslan DZ, Borge R, et al. Complication rates associated with pacemaker or implantable cardioverterdefibrillator generator replacements and upgrade procedures: results from the REPLACE registry. Circulation. 2010;122(16):1553-61. https://doi.org/10.11 61/CIRCULATIONAHA.110.976076

68. Krahn AD, Longtin Y, Philippon F, Birnie DH, Manlucu J, Angaran P, et al. Prevention of Arrhythmia Device Infection Trial: the PADIT Trial. J Am Coll Cardiol. 2018;72(24):3098-109.

69. Cowburn PJ, Patel H, Pipes RR, Parker JD. Contrast nephropathy post cardiac resynchronization therapy: an under-recognized complication with important morbidity. Eur J Heart Fail. 2005;7(5):899-903. https://doi.org/10.1 016/j.ejheart.2004.10.023.

70. Sharma G, Senguttuvan NB, Thachil A, Leong D, Naik N, Yadav R, et al. A comparison of lead placement through the subclavian vein technique with fluoroscopy-guided axillary vein technique for permanent pacemaker insertion. Can J Cardiol. 2012;28(5):542-6. https://doi.org/10.1016/j.cjca.2012.02.019.

71. Birnie DH, Healey JS, Wells GA, Verma A, Tang AS, Krahn AD, et al. Pacemaker or defibrillator surgery without interruption of anticoagulation. N Engl J Med. 2013;368(22):2084-93. https://doi.org/10.1056/NEJMoa1302946.

72. Spodick DH. Acute cardiac tamponade. N Engl J Med. 2003;349(7):684-90. https://doi.org/10.1056/NEJMra022643.

73. Biffi M, Moschini C, Bertini M, Saporito D, Ziacchi M, Diemberger I, et al. Phrenic stimulation. Circ Arrhythm Electrophysiol. 2009;2(4):402-10.

74. Wilkoff BL, Cook JR, Epstein AE, Greene HL, Hallstrom AP, Hsia H, et al. Dualchamber pacing or ventricular backup pacing in patients with an implantable defibrillator: the Dual Chamber and WI Implantable Defibrillator (DAVID) Trial. JAMA. 2002;288(24):3115-23. https://doi.org/10.1001/jama.288.24.3115.

75. Kirkfeldt RE, Johansen JB, Nohr EA, Jørgensen OD, Nielsen JC. Complications after cardiac implantable electronic device implantations: an analysis of a complete, nationwide cohort in Denmark. Eur Heart J. 2013;35(18):1186-94.

76. Guerra F, Shkoza M, Scappini L, Flori M, Capucci A. Role of electrical storm as a mortality and morbidity risk factor and its clinical predictors: a metaanalysis. EP Europace. 2013;16(3):347-53.

77. Takigawa M, Noda T, Kurita T, Aihara N, Yamada Y, Okamura H, et al. Predictors of electrical storm in patients with idiopathic dilated cardiomyopathy - how to stratify the risk of electrical storm. Circ J. 2010; 74(9):1822-9. https://doi.org/10.1253/circj.CJ-10-0092.

78. Daubert JP, Zareba W, Cannom DS, McNitt S, Rosero SZ, Wang P, et al. Inappropriate implantable cardioverter-defibrillator shocks in MADIT II: frequency, mechanisms, predictors, and sunvival impact. J Am Coll Cardiol. 2008:51(14):1357-65.

79. Israel CW, Serge BS. Electrical storm in patients with an implanted defibrillator: a matter of definition. Ann Noninvasive Electrocardiol. 2007; 12(4):375-82. https://doi.org/10.1111/j.1542-474X.2007.00187.x.

80. Ponikowski P, Voors AA, Anker SD, Bueno H, Cleland JGF, Coats AJS, et al. 2016 ESC guidelines for the diagnosis and treatment of acute and chronic heart failure: The Task Force for the Diagnosis and Treatment of Acute and Chronic Heart Failure of the European Society of Cardiology (ESC) developed with the special contribution of the Heart Failure Association (HFA) of the ESC. Eur Heart J. 2016;37(27):2129-200.

\section{Publisher's Note}

Springer Nature remains neutral with regard to jurisdictional claims in published maps and institutional affiliations. 